\title{
Performance Analysis of WLAN in Presence of UMTS
}

\author{
Hardavinder Singh \\ SBS State Technical Campus \\ Moga Road, Ferozepur-152004
}

\author{
Amit Grover \\ Assistant Professor \\ SBS State Technical Campus \\ Moga Road, Ferozepur-152004
}

\author{
Amardeep Chopra \\ (CA)
}

\begin{abstract}
In this paper the effect of interference of UMTS is analyzed on WLAN. The effect is analyzed by varying the speed of UMTS nodes. The interference is analyzed in terms of Video conferencing end to end delay, Throughput, Delay. Result shows that when there are no UMTS nodes, the performance is good, if UMTS nodes came in the network than due to interference performance decreases.
\end{abstract}

\section{Keywords}

WLAN, Mobility, interference, UMTS.

\section{INTRODUCTION}

Wireless processing is a quickly developing innovation providing clients with network availability with no kind of wire association in between the network. A LAN to which mobile users (customers) can associate and speak with the assistance of high recurrence radio waves to a specific degree than wires [1, 2, 4]. IEEE 802.11 is the standard for Wireless Local Area Networks produced by the Institute of Electrical and Electronics Engineers (IEEE). A wireless local area network (WLAN) is a remote PC arrange which give association in the middle of the at least two than two devices utilizing a wireless circulation strategy (frequently spreadrange) inside a some level of region, for example, a home, school, PC lab, or office building [3,5,6]. This gives clients the office to move around encompassed by a neighbourhood scope region and still be associated with the system, and can give a connection to the colossal web. The greater part late WLANs depend on IEEE 802.11 benchmarks, advertised under the Wi-Fi mark name $[7,12,14]$.

\subsection{WLAN STANDARDS}

IEEE 802.11 is the standard for Wireless Local Area Networks (WLANs) created by the Institute of Electrical and Electronics Engineers (IEEE) i.e. IEEE 802.11a is an in light of OFDM waveform at $5.8 \mathrm{GHz}$. what's more, gives conventions that permit sending and getting of data at rates of 1.5 to $54 \mathrm{Mbit} / \mathrm{s}$, IEEE $802.11 \mathrm{~b}$ is the moderate moving and smallest expensive open standard. At first, $802.11 \mathrm{~b}$ was the best standard as a result of its cost, yet as quicker gauges get a little sum costly, $802.11 \mathrm{~b}$ is losing prevalence. The $802.11 \mathrm{~b}$ standard utilized DSSS (Direct Sequence Spread Spectrum) tweak procedure. IEEE $802.11 \mathrm{~b}[10,11,13]$ has most extreme data rate $11 \mathrm{Mbps}$ and IEEE $802.11 \mathrm{~g}$ works in the $2.4 \mathrm{GHz}$ band (like 802.11b), however utilizes the same OFDM depending transmission plot as $802.11 \mathrm{a}$. It works at a most extreme physical layer bit rate of $54 \mathrm{Mbit} / \mathrm{s}$ select of forward blunder revision codes, or around $22 \mathrm{Mbit} / \mathrm{s}$ normal throughputs $[8,9,15]$.

\subsection{UMTS}

The Universal Mobile Telecommunications System (UMTS) is a third era versatile mobile cellular technology in view of the GSM standard. Created and kept up by the 3GPP (third Generation Partnership Project), UMTS is a part of the International Telecommunications Union IMT-2000 standard set and connect with theCDMA2000 standard set for systems relying upon the contending CDMA one innovation. UMTS utilizes wideband code division numerous get to (W-CDMA) radio get to offer greater spectral efficiency and bandwidth to mobile network operators. UMTS characterizes a total system framework, which contain the radio get to organize (UMTS Terrestrial Radio Access Network, or UTRAN), the centre system (Mobile Application Part) and the validation of clients by means of SIM (subscriber identity module) cards [10,11].

\section{LITERATURE SURVEY}

B.O. Sadiq et all [14] Designed a video conferencing application over an existing wireless network. To view if the existing wireless network was capable of running a video conferencing application they used The Riverbed Modeler 17.5 software. The Result analysis showed that, the modeled network has highest delay of 0.1225 bytes and lowest delay of 0.01 , which resulted to severe throughput degradation. The throughput result was just 80 (Mbps), which is below the desired throughput of 100 (Mbps) for an efficient Video Conferencing application over wireless network.

Gagro, Ivan et al [15] they used IEEE 802.11 a and b for Video streaming. They have designed private network to show some issues which unbalanced the throughput. They describe other factor that effects the performance of video streaming. They concluded that peer to peer connection is better than access point connection

\section{SIMULATION SETUP}

In this paper the effect of interference of UMTS nodes is analysed over WLAN. To analyse this effect WLAN network is made. In this network there scenarios are made (ground floor, first floor and second floor). There is also a server room in which two servers is placed in which one have VOIP application and other have VOD application as shown in fig 1. In ground floor 2 access point is used and 16 WLAN nodes is used as shown in fig 2 . In this scenario some nodes are giving VOD and some node having VoIP application. In first floor there are 4 access point is used and 12 WLAN nodes is used as shown in fig 3. In this scenario some nodes are giving VOD and some node having VoIP application. In $2^{\text {nd }}$ floor 1 access point is used and 5WLAN nodes are used as shown in fig 4. In this scenario some nodes are giving VOD and some node having VoIP application. To analyse the effect in first scenario in each floor there is UMTS mobile nodes is place which are moving at speed of $5 \mathrm{~m} / \mathrm{s}$. In second scenario UMTS mobile nodes are moving at speed of $7 \mathrm{~m} / \mathrm{s}$ and in third scenario some UMTS mobile nodes are moving at speed of $5 \mathrm{~m} / \mathrm{s}$ and some at $7 \mathrm{~m} / \mathrm{s}$. 


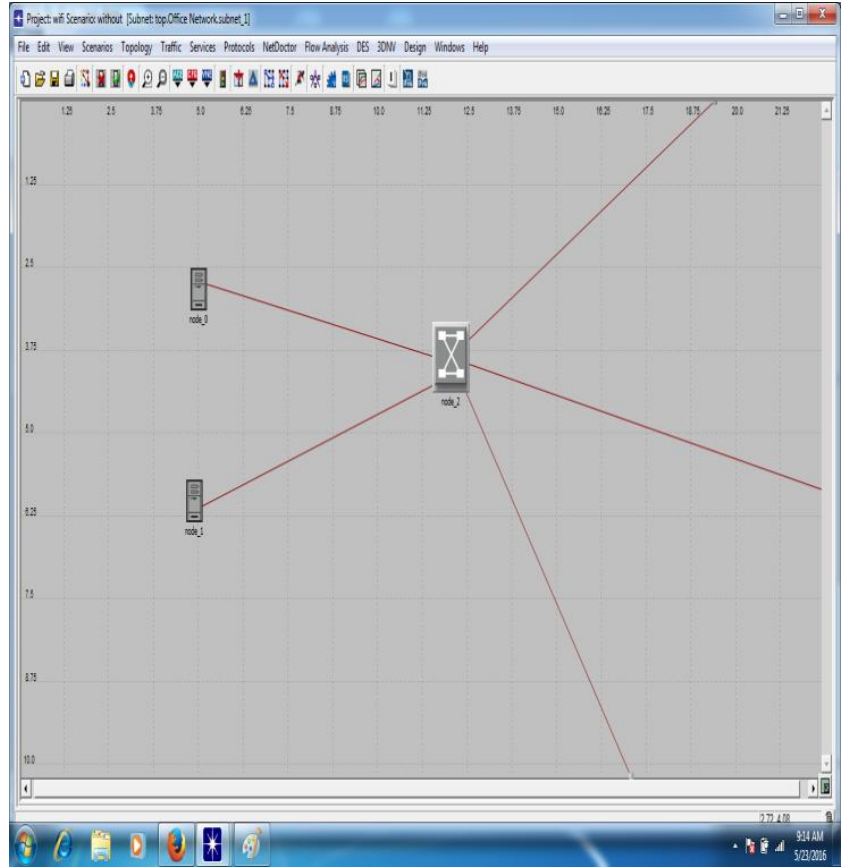

Figure 1: server room

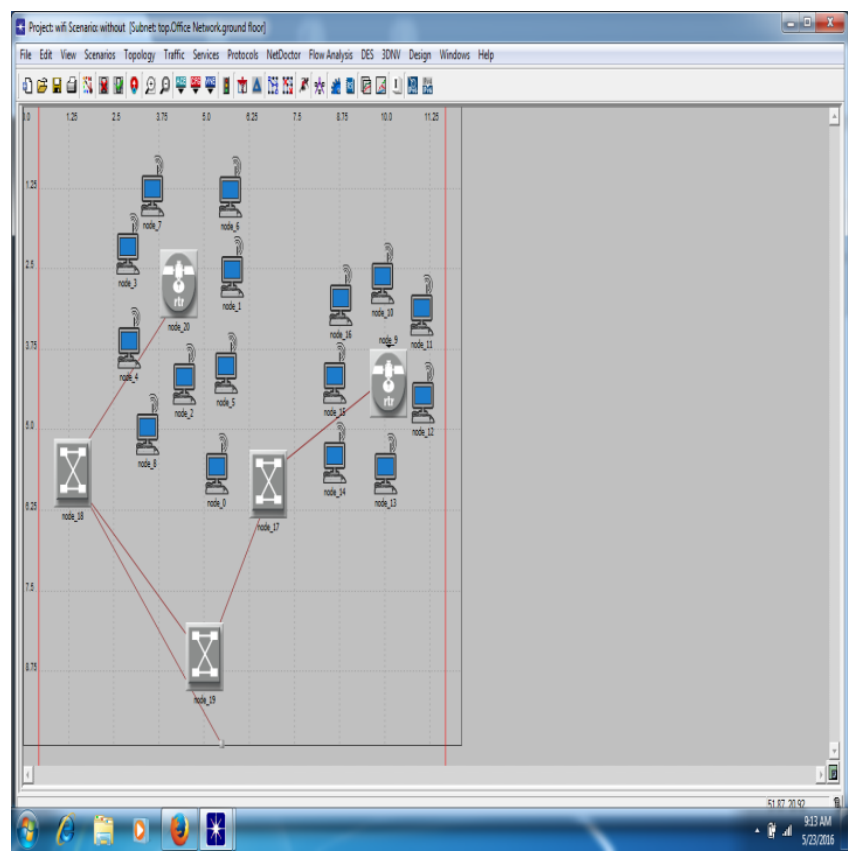

Figure 2: Ground floor

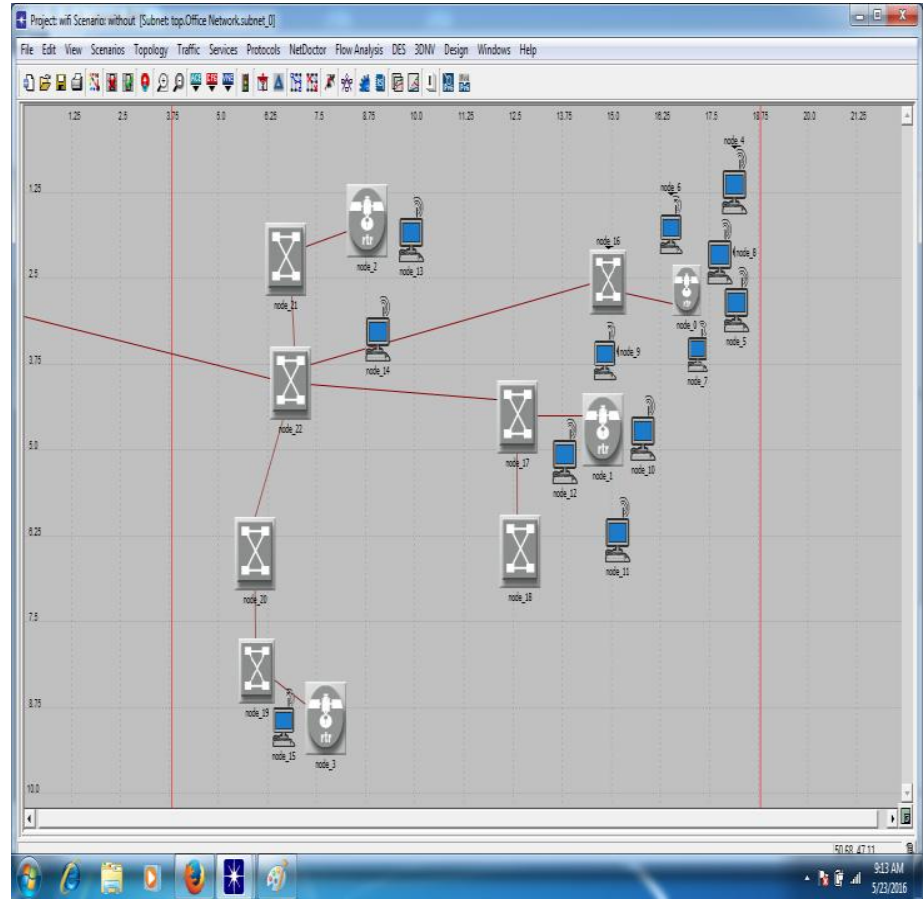

Figure 3: $1^{\text {st }}$ floor

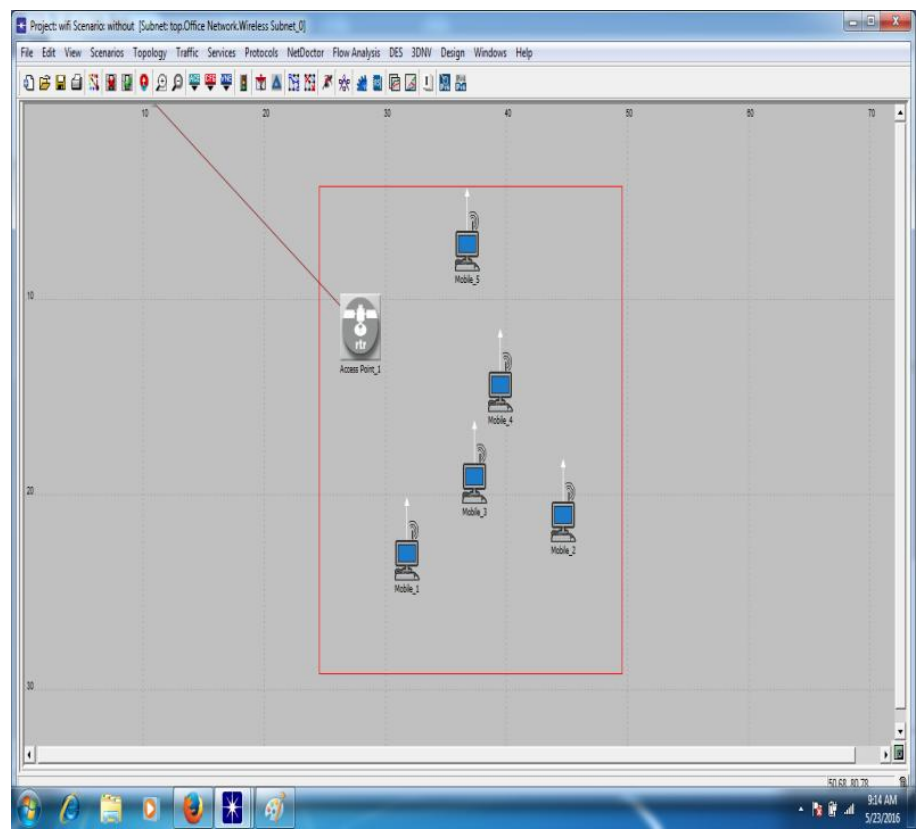

Figure 4: 2nd floor

\section{RESULTS}

In this paper the effect of mobility of UMTS nodes on WLAN performance is analysed in terms of Video conferencing end to end delay, Throughput, Delay. 


\subsection{Video Conferencing end to end delay}

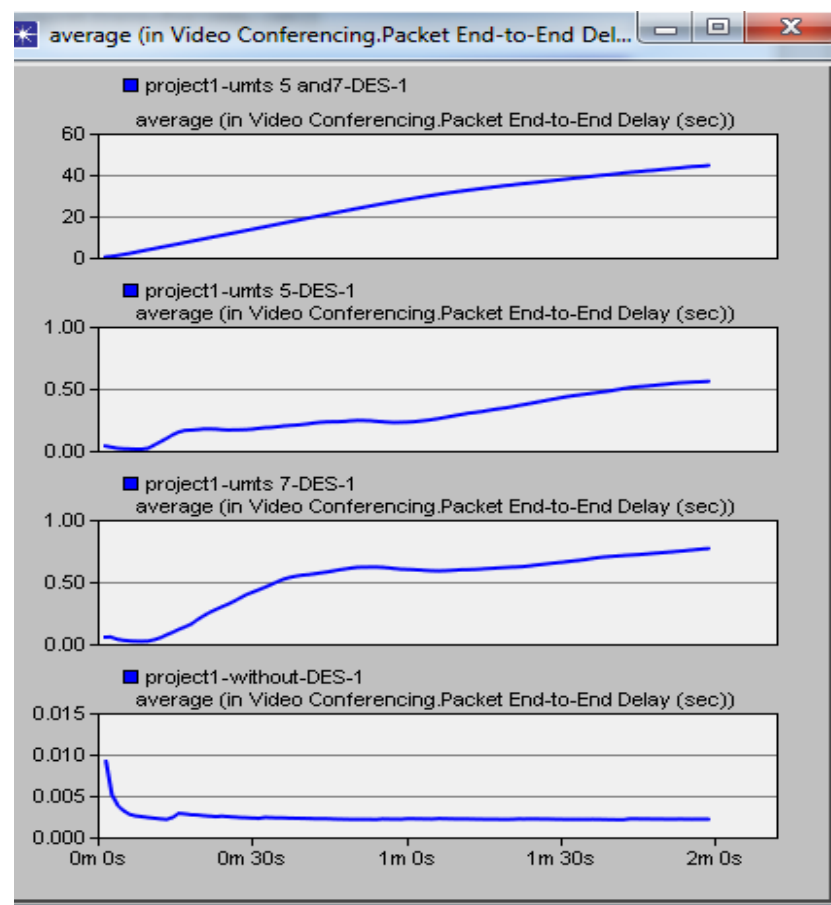

Figure 5: Result for Video Conferencing end to end delay

Fig5 shows that when only WLAN is used then performance is good which is $0.003 \mathrm{sec}$. But when UMTS nodes come in network performance decrease which is $0.7 \mathrm{sec}$ when nodes move at speed of $7 \mathrm{~m} / \mathrm{s}$. Further when nodes move at $5 \mathrm{~m} / \mathrm{s}$ it is $0.6 \mathrm{sec}$. At mix speed it is $50 \mathrm{sec}$. Fig shows that the performance of WLAN without interference is better because more delay means more no. Of packets are transmitted.

\subsection{Throughput}

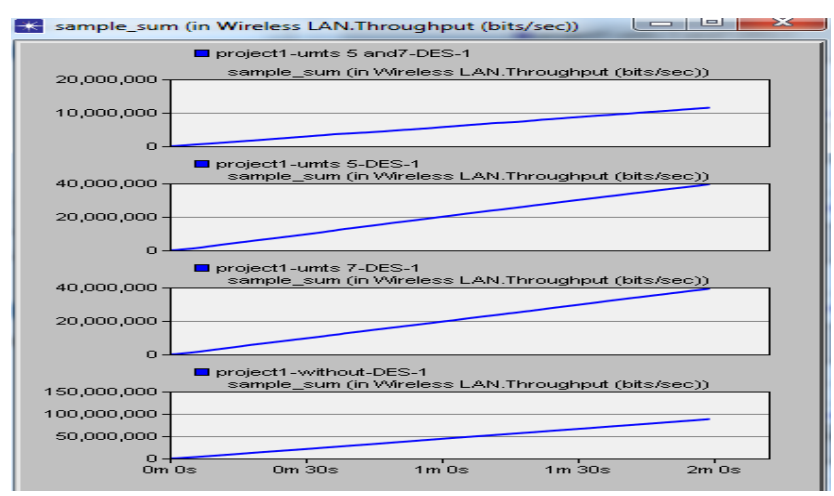

Figure 6: Result for Throughput

Figure 6 shows that when only WLAN is used then performance is good which is $90000000 \mathrm{bits} / \mathrm{sec}$. But when UMTS nodes come performance decrease which is $40,000,000 \mathrm{bits} / \mathrm{sec}$ when nodes are moving at speed of $5 \mathrm{~m} / \mathrm{s}$ and $7 \mathrm{~m} / \mathrm{s}$, it is $20,000,000 \mathrm{bits} / \mathrm{sec}$ when nodes are moving at mix speed of $5 \mathrm{~m} / \mathrm{s}$ and $7 \mathrm{~m} / \mathrm{s}$.

\subsection{Delay}

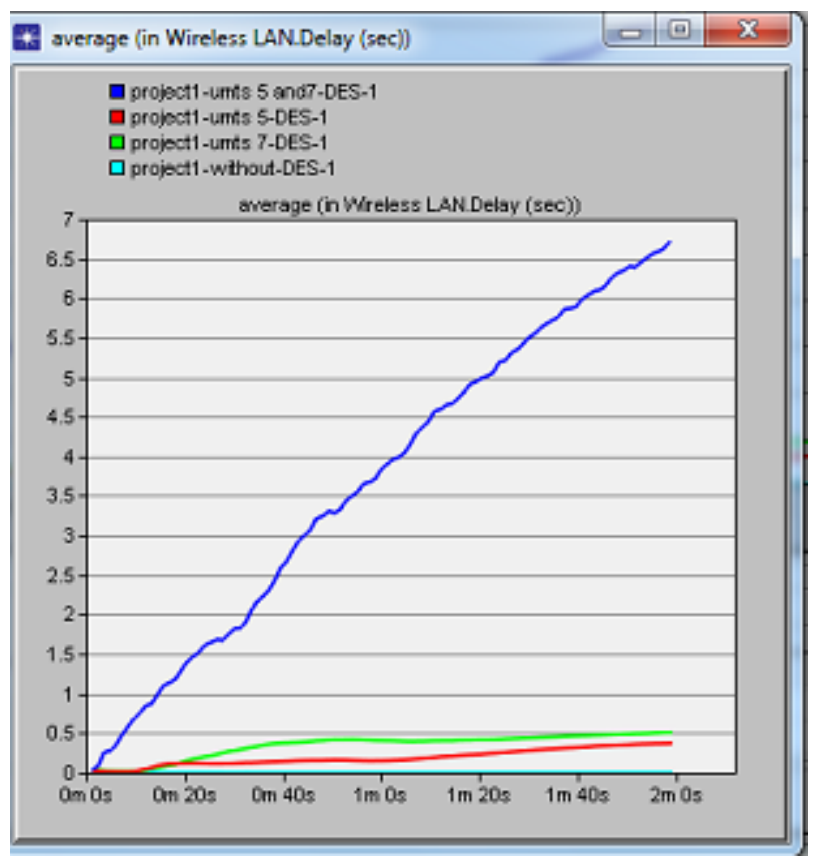

Figure 7: Result for Delay

Fig7 shows that when only WLAN is used then performance is good which is $0.2 \mathrm{sec}$. But when UMTS nodes at the speed of $5 \mathrm{~m} / \mathrm{s}$ delay is $0.3 \mathrm{sec}$. Further by change in mobility when nodes move at the speed of $7 \mathrm{~m} / \mathrm{s}$ it is $0.5 \mathrm{sec}$. when nodes move at mix speed of $5 \mathrm{~m} / \mathrm{sec}$ and $7 \mathrm{~m} / \mathrm{sec}$ it higher $6.7 \mathrm{sec}$.

\section{CONCLUSION}

In this paper the effect of interference and variation of speed of UMTS on WLAN is analysed. The performance is also analysed by moving nodes of UMTS at different speed. The performance of WLAN in presence of UMTS is analysed in terms of Video conferencing end to end delay, Throughput, Delay. Result shows that when there is no interference of UMTS then performance of WLAN is better but when UMTS nodes come then performance decrease. Result also shows that with increase in speed performance decreases.

\section{REFERENCES}

[1] Ipatovs, A., and E. Petersons. "Performance Evaluation of WLAN depending on Number of Workstations and Protocols." Elektronika ir Elektrotechnika72.8 (2015): 15-18.Network” Elsevier Physics Procedia 33 ( 2012 ) $1588-1595$

[2] Cao, Y. F., S. W. Cheung, and T. I. Yuk. "A multiband slot antenna for GPS/WiMAX/WLAN systems." Antennas and Propagation, IEEE Transactions on 63.3 (2015): 952-958.

[3] Hosoya, Ken'ichi, et al. "Multiple sector ID capture (MIDC): A novel beamforming technique for $60-\mathrm{GHz}$ band multi-Gbps WLAN/PAN systems."Antennas and Propagation, IEEE Transactions on 63.1 (2015): 81-96.

[4] Trifunovic, Sacha, et al. "WLAN-Opp: Ad-hoc-less opportunistic networking on smartphones." Ad Hoc Networks 25 (2015): 346-358.

[5] Hassan, Inuwa Musa, Habib Ullah Khan, and VV Madhavi Lalitha. 
[6] "Pedagogical potentials of IEEE 802.11 WLAN to Nigerian universities: a case study of the university of Uyo." International Journal of Information and Education Technology 6.4 (2016): 256.

[7] Sbit, Selma, Mohamed Bechir Dadi, and Belgacem Chibani. "Co and Adjacent Channel Interference Evaluation in GSM and UMTS Cellular Networks." cell 4.11 (2015).

[8] Siregar, Y. A. "Frequency interference analysis between UMTS and CDMA 2000 in $2.1 \mathrm{GHz}$ frequency band." 2015 1st International Conference on Wireless and Telematics (ICWT). IEEE, 2015.

[9] Bagubali, A., et al. "Integration of UMTS with WLAN Using Intermediate IMS Network." Proceedings of the International Conference on Soft Computing Systems. Springer India, 2016.

[10] Tripathi, Shashank, and A. K. Jain. "WLAN and UMTS QoS: A Survey."Journal of Telecommunication, Switching Systems and Networks 1.3 (2015): 20-29.

[11] Wang, Shang, and Zhengwei Du. "A dual-antenna system for LTE/WWAN/WLAN/WiMAX smartphone applications." Antennas and Wireless Propagation Letters, IEEE 14 (2015): 1443-1446.

[12] Trestian, Ramona, Olga Ormond, and Gabriel-Miro Muntean. "Performance evaluation of MADM-based methods for network selection in a multimedia wireless environment." Wireless Networks 21.5 (2015): 17451763.

[13] Loni, Janabeg, and Vinod Kumar Singh. "Development of Bandwidth Enhanced Microstrip Patch Antenna for UMTS Application." Journal of Microwave Engineering \& Technologies (ISSN: 2349-90012015 1.1.

[14] Sumiła, Marek, and Andrzej Miszkiewicz. "Analysis of the Problem of Interference of the Public Network Operators to GSM-R." Tools of Transport Telematics. Springer International Publishing, 2015. 253-263.

[15] Sadiq, B. O., et al. "Service Level Analysis of Video Conferencing over Wireless Local Area Network." (2015).

[16] Gagro, Ivan, Riko Luša, and Vanesa Čačković B. Sc EE. "MPEG-4 video transfer over IEEE 802.11 WLAN." (2013). 